\title{
Non-isothermal crystallization kinetics of partially miscible ethylene-vinyl acetate copolymer/low density polyethylene blends
}

\author{
J. Jin, S. J. Chen, J. Zhang1 \\ Department of Polymer Science and Engineering, College of Materials Science and Engineering, Nanjing University of \\ Technology, Nanjing 210009, People's Republic of China
}

Received 25 October 2009; accepted in revised form 16 December 2009

\begin{abstract}
The non-isothermal crystallization kinetics of ethylene-vinyl acetate copolymer (EVA, 14 wt $\%$ vinyl acetate content), low density polyethylene (LDPE) and their binary blends with different blending ratio were investigated via differential scanning calorimetry. Jeziorny theory and Mo's method were utilized in evaluating the crystallization behavior of both neat materials successfully. In the primary crystallization stage both EVA and LDPE had three-dimensional spherulitic growth mechanism. Apparently the crystallization rate of LDPE was faster than that of EVA at a low cooling rate. Increase in cooling rate limited the spherulites' growth, which narrowed their rate difference. Influences from blending on the crystallization kinetics of each component in EVA/LDPE mixture were evaluated by Kissinger's activation energy $(\Delta E)$ and Khanna's crystallization rate coefficient $(C R C)$. Inter-molecular interaction in the melt increased the $\Delta E$ of both EVA and LDPE components at the beginning of cooling. During the primary crystallization stage of LDPE, dilution effect from EVA facilitated the crystal growth in LDPE. Co-crystallization between EVA component and the secondary crystallization stage of LDPE component also increased the $C R C$ of EVA. In blend of EVA/LDPE $=7 / 3$, LDPE obtained the maximal $C R C$ value of $174.2 \mathrm{~h}^{-1}$. Results obtained from various approaches accorded well with each other, which insured the rationality of conclusion.
\end{abstract}

Keywords: thermal properties, ethylene-vinyl acetate copolymer, low density polyethylene, polymer blend, non-isothermal crystallization kinetics

\section{Introduction}

Ethylene-vinyl acetate copolymer (EVA) has good transparency, flexibility and good oxygen barrier properties [1]. Blending EVA with low density polyethylene (LDPE) could increase the elasticity of material, and optimize its combination with inorganic materials [2]. It is an economical and efficient alternative to the development of new polymer materials [3-5]. The crystallizable units in both EVA and LDPE are ethylene chain segments [6]. To EVA, polar vinyl-acetate units (VAc) are introduced randomly into the backbone of copolymer, acting as intervals of ethylene chain segments with various lengths. As for LDPE, the short branches could also hinder its crystallization behavior while chains arranging into lattices. This could lead to multiple crystallization stages based on complex thermal history. Regarding their binary blends, the partial miscibility has been studied in our previous works via isothermal crystallization [7]. However, their crystallization under non-isothermal conditions would be more complicated than the ideal isothermal situation. This is of importance both in theoretical research and industrial manufacturing fields. Influences from cooling rate, heat transmission lags and thermal gradients within samples 
must be taken into account, which are all vital factors referring to the overall crystallization properties of polymer.

Non-isothermal crystallization study via differential scanning calorimetry (DSC) provides not only a good controlled and reproducible procedure, but also an access to the quantitative analysis of crystallization kinetics. Many widely used kinetic models such as Jeziorny theory [8], Ziabicki theory [9], Ozawa model [10] and Mo's method [11, 12], which were mostly derived from the classical Avrami equation in isothermal condition, have been successfully performed in many single polymers, polymer blends and composites. For instance, Shi studied the influence of VAc content on the crystallization rate of single EVA [13]; nonisothermal crystallization kinetics of PP/EVA blends were reported by Goodarzi et al. [14]; Li et al. [15] also researched the nucleation effect of inorganic fillers in EVA/carbon nanotube composites. However, the non-isothermal crystallization kinetics studies in EVA/LDPE binary mixtures were rarely reported. Their partial miscibility resulted in apparent overlaps of exotherms during cooling process. Their asymmetric figures also restricted the fitting accuracy of peak separation. It was inappropriate to obtain the separate enthalpy integration of each component for further calculation. A model with a parameter of crystallization rate coefficient $(C R C)$ proposed by Khanna [16] could be utilized. In this work, the non-isothermal crystallization kinetics and the subsequent melting of neat EVA, LDPE, and their binary blends with various ratios were studied via Jeziorny theory and Mo's method. Influences from their partial miscibility on the crystallization behavior and mechanism of each component in blends were investigated by Kissinger's activation energy and Khanna's CRC model, respectively.

\section{Experimental}

\subsection{Materials}

Ethylene-vinyl acetate copolymer with $14 \mathrm{wt} \% \mathrm{VAc}$ (EVA 14-2) was supplied by Beijing Organic Chemistry Plant, Beijing, China; the melting flow rate (MFR) is $2.0 \mathrm{~g} / 10 \mathrm{~min}$, the density is $0.94 \mathrm{~g} / \mathrm{cm}^{3}$. Low density polyethylene (LDPE 2426H) was obtained from BASF-YPC Co. Ltd., Nanjing,
China. Its MFR is $2.0 \mathrm{~g} / 10 \mathrm{~min}$, the density is about $0.92 \sim 0.93 \mathrm{~g} / \mathrm{cm}^{3}$.

\subsection{Preparation of blends}

Blends of EVA/LPDE with various ratios were prepared in a $60 \mathrm{ml}$ Rheomix internal mixer (Shanghai Kechuang XSS-300, China); the melt compounding was performed at $135^{\circ} \mathrm{C}$ for $10 \mathrm{~min}$; the rotor speed is $30 \mathrm{rpm}$ and the total mixing weight was about $50 \mathrm{~g}$ per batch. Samples were designated as $\mathrm{EVA}, \mathrm{EVA} / \mathrm{LDPE}=7 / 3, \mathrm{EVA} / \mathrm{LDPE}=5 / 5, \mathrm{EVA} /$ $\mathrm{LDPE}=3 / 7$ and LDPE for various EVA mass ratios in blend, respectively.

\subsection{Differential scanning calorimetry}

The non-isothermal crystallization and the subsequent melting behaviors were carried out by a differential scanning calorimeter (TA Q200, USA). Samples weighing about $10 \mathrm{mg}$ were cut off for characterization. Nitrogen purge gas with a flux of $50 \mathrm{ml} / \mathrm{min}$ was used to prevent thermal degradation of samples during scanning. In order to eliminate residual volatile impurities and the small crystals, all samples were first quickly heated (at $40^{\circ} \mathrm{C} / \mathrm{min}$ ) up to $150^{\circ} \mathrm{C}$ and held isothermally for 3 minutes. Then they were cooled down from melt to $0^{\circ} \mathrm{C}$ at five different cooling rates: $2.5,5,10,15$ and $20^{\circ} \mathrm{C} / \mathrm{min}$, respectively. The subsequent melting process after each step of non-isothermal cooling was executed by heating run from 0 to $150^{\circ} \mathrm{C}$ at a constant rate of $10^{\circ} \mathrm{C} / \mathrm{min}$.

\section{Results and discussion}

\subsection{Non-isothermal crystallization}

Figure 1 illustrates the non-isothermal cooling traces of all samples. Molecular chain segments crystallized slower than the continuous temperature dropping. And their movability degenerated at a lower ambient temperature. Such lag between them was magnified under a higher cooling rate [17]. Exothermic peaks exhibited broader figure and shifted gradually to a lower temperature. Multiple exothermic characteristics were observed both in neat EVA and LDPE: a sharp major exothermic peak followed by a following broad peak/shoulder with apparent lagging tail. For EVA, the randomly 

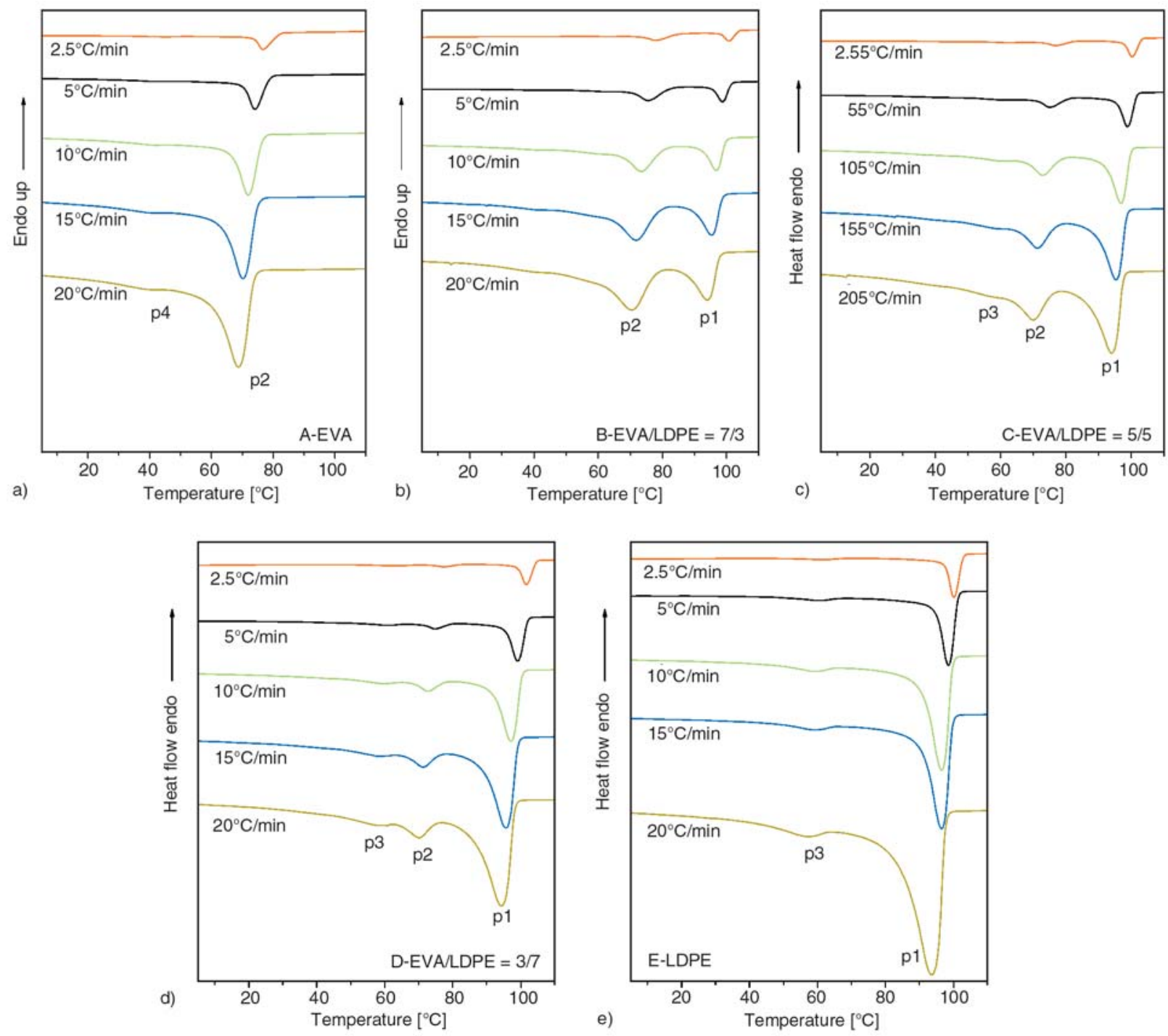

Figure 1. Non-isothermal crystallization exotherms of blends at different cooling rate (A-EVA, B-EVA/LDPE $=7 / 3$, $\mathrm{C}-\mathrm{EVA} / \mathrm{LDPE}=5 / 5, \mathrm{D}-\mathrm{EVA} / \mathrm{LDPE}=3 / 7, \mathrm{E}-\mathrm{LDPE}$ )

introduced VAc units acted as the interval in the backbone of copolymer, which fractionated ethylene chain segments by various crystallizable lengths [18]. The major exothermic peak represented the fusion of lamellae arranged by a portion of chain segments of the highest crystallizablity, indicating the primary crystallization stage. While those defective chain segments were repelled to the surface of the existing crystal. They were forced to crystallize under a lower temperature later with more deficiency during arrangement, thus formed the secondary crystallization region [7]. It has been widely accepted that the short ethylene branches in LDPE could inhibit its overall crystallization behavior [19]. Similar molecular fractionation and secondary crystallization stage during non-isothermal crystallization were even more remarkable in neat LDPE. In traces of blends, the peak of EVA component overlapped partially with LDPE component. The secondary crystallization shoulder in EVA component became imperceptible in all blends; the secondary crystallization peak of LDPE component was also affected. As the LDPE ratio increased in blends, its exotherms grew to a larger and sharper figure.

\subsubsection{Non-isothermal crystallization of neat materials}

The non-isothermal crystallization kinetics of neat EVA and LDPE were first studied. Data in Table 1 show that the onset crystallization temperature $\left(T_{c}^{o n}\right)$ of LDPE was about $20^{\circ} \mathrm{C}$ higher than that of EVA. The secondary crystallization peak tempera- 
Table 1. Non-isothermal crystallization data of neat EVA and LDPE

\begin{tabular}{|c|c|c|c|c|c|c|c|c|c|}
\hline Sample & $\mathrm{D}\left[{ }^{\circ} \mathrm{C} / \mathrm{min}\right]$ & $\mathbf{T}_{\mathbf{c}}^{\mathbf{f}}\left[{ }^{\circ} \mathbf{C}\right]$ & $\mathbf{T}_{\mathbf{c}}^{\mathbf{p}^{4}}\left[{ }^{\circ} \mathbf{C}\right]$ & $\mathbf{T}_{\mathbf{c}}^{\mathbf{p} 3}\left[{ }^{\circ} \mathbf{C}\right]$ & $\mathbf{T}_{\mathbf{c}}^{\mathbf{p}^{2}\left[{ }^{\circ} \mathbf{C}\right]}$ & $\mathbf{T}_{\mathbf{c}}^{\mathbf{p} 1}\left[{ }^{\circ} \mathbf{C}\right]$ & $\mathbf{T}_{\mathrm{c}}^{\mathrm{on}}\left[{ }^{\circ} \mathbf{C}\right]$ & $\Delta \mathbf{T}_{\mathbf{c}}\left[{ }^{\circ} \mathbf{C}\right]$ & $\Delta \mathbf{H}_{\mathrm{c}}[\mathrm{J} / \mathrm{g}]$ \\
\hline \multirow{5}{*}{ EVA } & 2.5 & 30.7 & 44.0 & - & 75.6 & - & 81.1 & 50.4 & 79.2 \\
\hline & 5.0 & 28.7 & 43.2 & - & 74.1 & - & 78.8 & 50.1 & 77.3 \\
\hline & 10.0 & 28.5 & 42.1 & - & 71.9 & - & 76.4 & 48.0 & 75.2 \\
\hline & 15.0 & 26.7 & 41.8 & - & 70.3 & - & 74.9 & 48.2 & 73.8 \\
\hline & 20.0 & 25.4 & 39.5 & - & 68.7 & - & 73.7 & 48.3 & 72.6 \\
\hline \multirow{5}{*}{ LDPE } & 2.5 & 50.9 & - & 61.3 & - & 100.1 & 102.8 & 51.9 & 123.7 \\
\hline & 5.0 & 49.2 & - & 60.3 & - & 98.5 & 101.3 & 52.1 & 124.2 \\
\hline & 10.0 & 46.0 & - & 59.0 & - & 96.5 & 99.7 & 53.7 & 129.3 \\
\hline & 15.0 & 44.4 & - & 58.2 & - & 95.0 & 98.5 & 54.1 & 118.4 \\
\hline & 20.0 & 41.3 & - & 57.2 & - & 93.6 & 97.6 & 56.3 & 125.7 \\
\hline
\end{tabular}

$D$ : cooling rate; $T_{c}^{o n}$ : onset crystallization temperature; $T_{c}^{p 1}$ : peak crystallization temperature of the primary crystallization in LDPE; $T_{c}^{p 2}$ : peak crystallization temperature of primary crystallization in EVA; $T_{c}^{p 3}$ : peak crystallization temperature of secondary crystallization in LDPE; $T_{c}^{p 4}$ : peak crystallization temperature of secondary crystallization in EVA; $T_{c}^{f}$ : final crystallization temperature; $\Delta T_{c}=T_{c}^{o n}-T_{c}^{f}$; $\Delta H_{c}$ : crystallization enthalpy of polymer

ture $\left(T_{c}^{p 3}\right)$ of LDPE was about $17^{\circ} \mathrm{C}$ higher than the corresponding parameter of EVA $\left(T_{c}^{p 4}\right)$. The crystallization enthalpy $\left(\Delta H_{c}\right)$ of EVA decreased slightly along with the increase in cooling rate.

\section{A-Jeziorny theory}

The classical Avrami equation [20-22] relates to the amount or fraction of un-crystallized material that remains after time $t$, which has been commonly utilized in describing isothermal crystallization kinetics of polymer. It is given by Equation (1):

$$
1-X_{t}=\exp \left(-Z_{t} t^{n}\right)
$$

where $Z_{t}$ is the crystallization rate constant, which involves the contribution from both nucleation and crystal growth. $n$ represents the Avrami exponent, representing the mechanism and dimensional geometry of crystal growth. $X_{t}$ stands for the relative crystallinity, which is set as a function of time $t$ according to Equation (2):

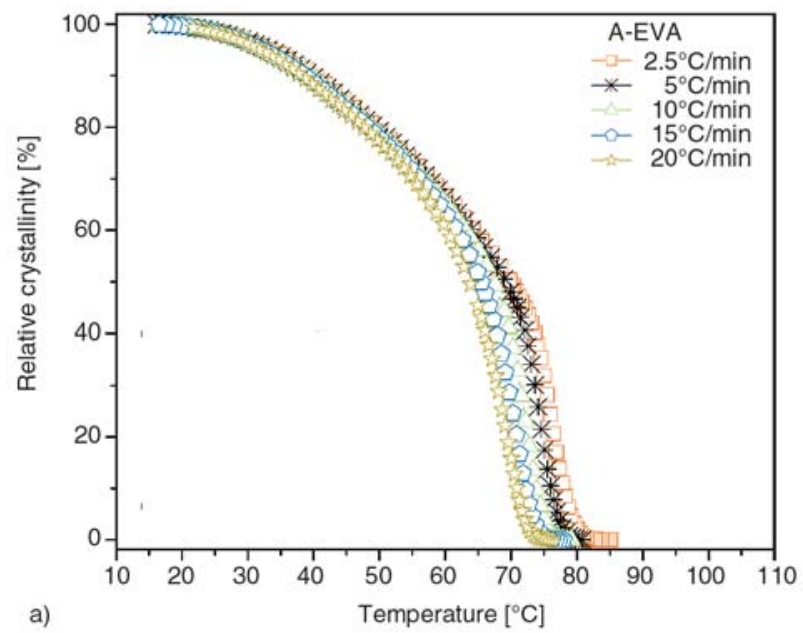

$X_{t}=\frac{\int_{t_{0}}^{t}\left(\frac{\mathrm{d} H_{c}}{\mathrm{~d} t}\right) \mathrm{d} t}{\int_{t_{0}}^{t_{\infty}}\left(\frac{\mathrm{d} H_{c}}{\mathrm{~d} t}\right) \mathrm{d} t} \cdot 100 \%$

where $t_{0}$ and $t_{\infty}$ mean the onset and completion time of the specific crystallization stage, respectively. $\mathrm{d} H_{c}$ is the enthalpy of the crystallization released during an infinitesimal time range $\mathrm{d} t$. In this experiment, for a chosen cooling rate, the heat flow integration of relative crystallinity calculation can be firstly recorded as a function of temperature $T$ [23], see Equation (3):

$X_{T}=\frac{\int_{T_{0}}^{T}\left(\frac{\mathrm{d} H_{c}}{\mathrm{~d} T}\right) \mathrm{d} T}{\int_{T_{0}}^{T_{\infty}}\left(\frac{\mathrm{d} H_{c}}{\mathrm{~d} T}\right) \mathrm{d} T} \cdot 100 \%$

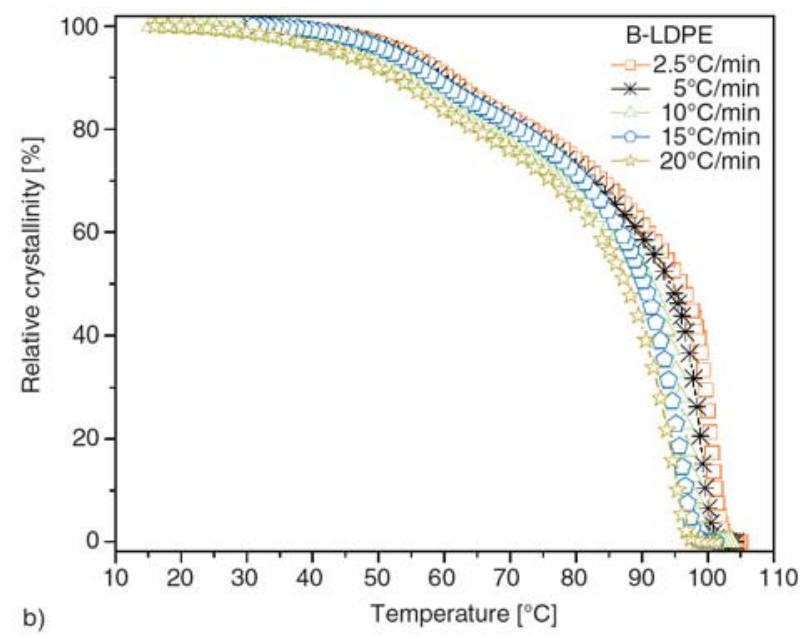

Figure 2. Plots of $X_{t}$ versus $T$ for neat EVA and LDPE during non-isothermal crystallization stage (A-EVA, B-LDPE) 

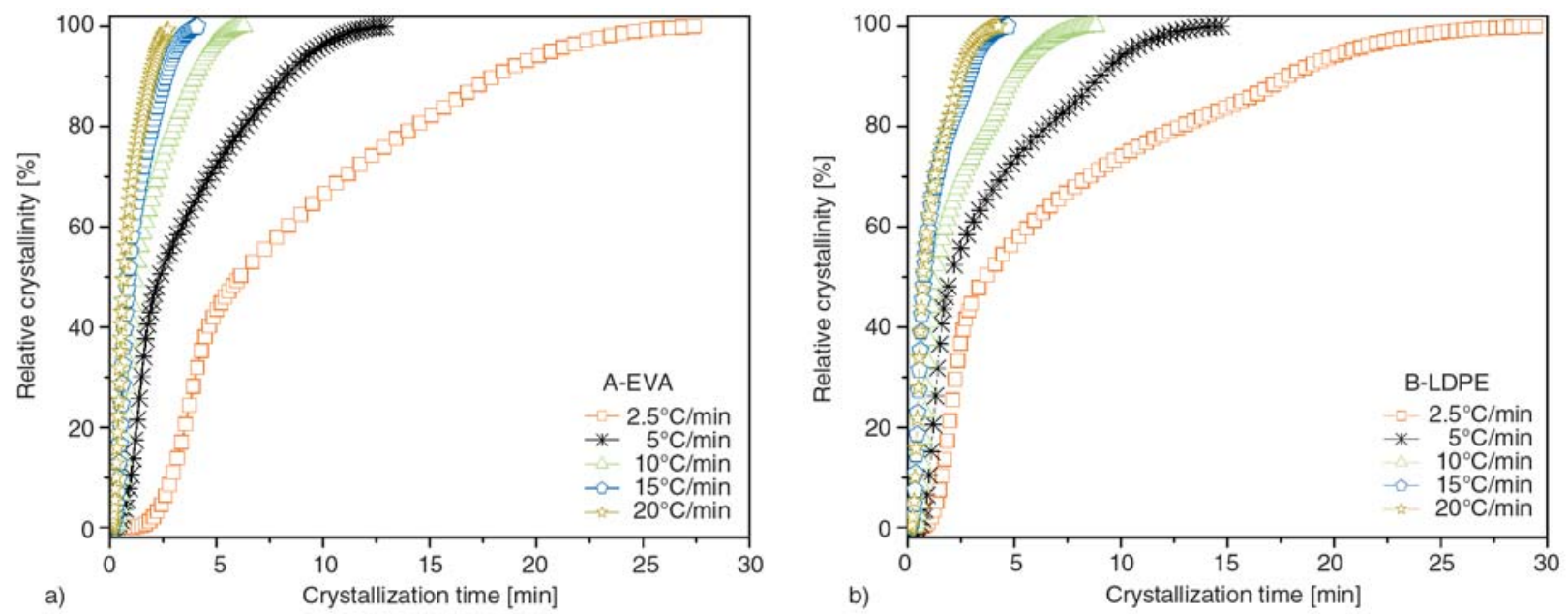

Figure 3. Plots of $X_{t}$ versus $t$ for neat EVA and LDPE during non-isothermal crystallization stage (A-EVA, B-LDPE)

$T_{0}$ and $T_{\infty}$ in Equation (3) are the onset and completion temperature of the crystallization stage, respectively. Figure 2 illustrates the development of the relative crystallinity to $T$ of two neat materials at varying cooling rate.

The $T$-axis can be transformed into the $t$-axis as shown in Figure 3. Crystallization time can be calculated from the following Equation (4), in which the $D$ stands for the cooling rate $(2.5,5,10,15$ and $20^{\circ} \mathrm{C} / \mathrm{min}$, respectively):

$t=\frac{\left|T_{0}-T\right|}{D}$

In the primary crystallization, relative crystallinity increases acutely along with $t$. The half crystallization time $t_{1 / 2}$, representing the time needed to achieve $50 \%$ of the entire crystallization progress, keeps lower than $5 \mathrm{~min}$ in all cases. However, after $X_{t}$ overreached about $40 \%$, the secondary crystal-

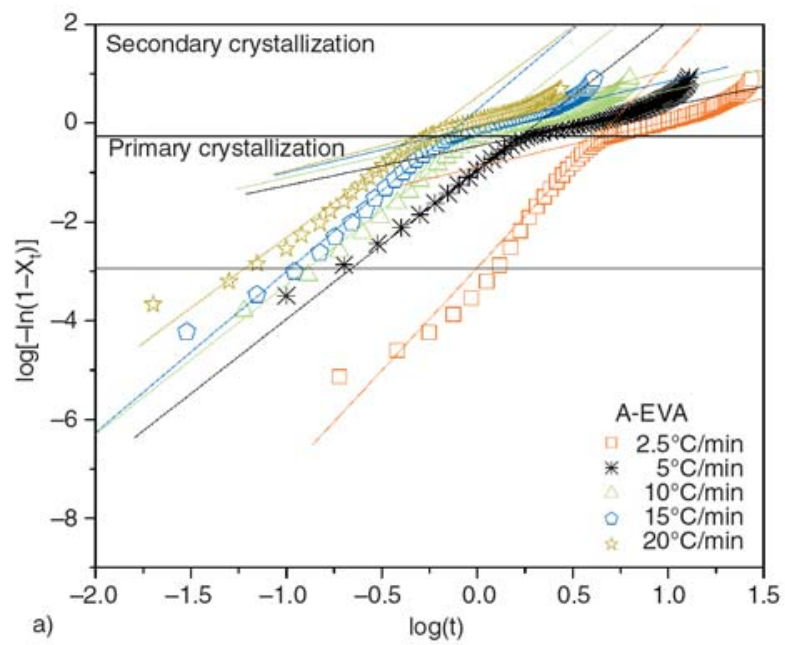

lization stage of EVA and LDPE began. It took much longer time to complete the overall crystallization stage. Such characteristic was also reported in crystallization kinetics of metallocene polyethylene [24].

The double-logarithmic form of the Equation (1) is given by Equation (5):

$\log \left[-\ln \left(1-X_{t}\right)\right]=\log Z_{t}+n \log (t)$

Plotting $\log \left[-\ln \left(1-X_{t}\right)\right]$ against $\log (t)$ for each $D$, the primary linear section obtained from Equation (5) enables one to obtain the Avrami exponent $n$ and the crystallization rate constant $Z_{t}$ from the slope and the intercept, respectively. Considering the influence from continuously changing temperature in the non-isothermal crystallization, parameters do not have the same physical meaning as in the iso-thermal situation. $Z_{t}$ should be corrected for the non-isothermal situation by Equation (6):

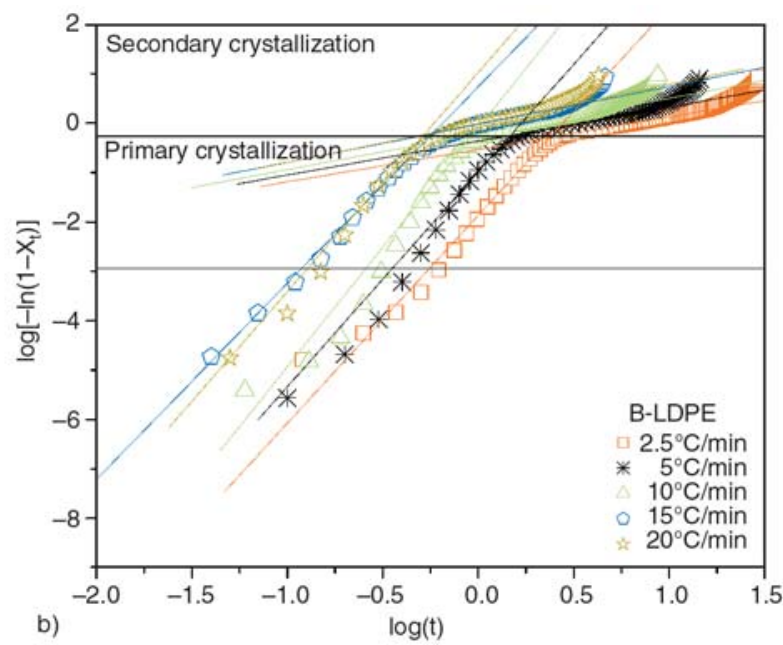

Figure 4. Plots of $\log \left[-\ln \left(1-X_{t}\right)\right]$ versus $\log (t)$ for EVA and LDPE as received at various cooling rate (A-EVA, B-LDPE) 
Table 2. Data from Jeziorny theory in non-isothermal crystallization kinetic analysis

\begin{tabular}{|c|c|c|c|c|c|c|c|}
\hline \multirow{2}{*}{ Sample } & \multirow{2}{*}{$\begin{array}{c}\mathbf{D} \\
{\left[{ }^{\circ} \mathbf{C} / \mathbf{m i n}\right]}\end{array}$} & \multicolumn{3}{|c|}{ Primary crystallization } & \multicolumn{2}{|c|}{ Secondary crystallization } & \multirow{2}{*}{$\begin{array}{c}\mathbf{t}_{1 / 2} \\
{[\mathrm{~min}]}\end{array}$} \\
\hline & & $\mathbf{Z}_{\mathrm{c}}\left[\mathrm{min}^{-1}\right]$ & $\mathbf{n}$ & Adj. $\mathbf{R}^{2}$ & n' & Adj. $\mathbf{R}^{2}$ & \\
\hline \multirow{5}{*}{ EVA } & 2.5 & 0.06 & 4.52 & 0.9960 & 0.93 & 0.9996 & 6.10 \\
\hline & 5.0 & 0.64 & 3.01 & 0.9998 & 0.79 & 0.9997 & 2.34 \\
\hline & 10.0 & 0.96 & 3.40 & 0.9986 & 0.87 & 0.9995 & 1.21 \\
\hline & 15.0 & 1.05 & 3.40 & 0.9928 & 0.94 & 0.9994 & 0.85 \\
\hline & 20.0 & 1.07 & 2.98 & 0.9907 & 0.96 & 0.9993 & 0.66 \\
\hline \multirow{5}{*}{ LDPE } & 2.5 & 0.16 & 4.80 & 0.9989 & 0.67 & 0.9997 & 3.67 \\
\hline & 5.0 & 0.66 & 5.79 & 0.9983 & 0.69 & 0.9998 & 2.00 \\
\hline & 10.0 & 1.08 & 6.57 & 0.9978 & 0.75 & 0.9974 & 1.29 \\
\hline & 15.0 & 1.20 & 4.79 & 0.9919 & 0.76 & 0.9994 & 0.85 \\
\hline & 20.0 & 1.25 & 5.99 & 0.9918 & 0.77 & 0.9994 & 0.73 \\
\hline
\end{tabular}

$D$ : cooling rate; $Z_{c}$ : non-isothermal crystallization rate constant modified by Jeziorny; $n$ : Avrami index in the primary crystallization stage; $n$ ': Avrami index in the secondary crystallization stage; $t_{1 / 2}$ : half crystallization time; $A d j$. $R^{2}$ : adjust $R^{2}$ of plots fitting

$$
\ln Z_{c}=\frac{\ln Z_{t}}{D}
$$

$Z_{c}$ was modified by Jeziorny [8] in Equation (6), which stands for the non-isothermal crystallization rate constant. And $n$ is designated as the apparent Avrami exponent.

Figure 4 exhibites plots of $\log \left[-\ln \left(1-X_{t}\right)\right]$ against $\log (t)$ of neat EVA and LDPE, respectively. Plots above could be separated into three stages along with $\log (t)$ : the nucleation process, the primary crystallization stage and the secondary crystallization stage. The primary crystallization showed approximately linear shape. In the secondary crystallization stage, all plots deviated from the former direction, and exhibited another approximately linear shape with gentley slopes.

The values of $Z_{c}, n$ and $t_{1 / 2}$ in EVA and LDPE were listed in Table 2. Good linear fitting results of both the primary and secondary crystallization are obtained (Adj. $R^{2}>0.99$ ). In the $2.5^{\circ} \mathrm{C} / \mathrm{min}$ cooling case, the $Z_{c}$ of the primary crystallization stage in LDPE $\left(0.16 \mathrm{~min}^{-1}\right)$ was much higher than that in EVA $\left(0.06 \mathrm{~min}^{-1}\right)$. Increase in cooling rate limited the further spherulites' growth, which narrowed the rate difference between EVA and LDPE. Similar shrinking tendency was also observed in $t_{1 / 2}$. When beeing cooled at a rate of $20^{\circ} \mathrm{C} / \mathrm{min}, t_{1 / 2}$ of EVA was even lower than LDPE. It has been accepted that, a high ambient temperature would inhibit the nucleation but facilitate the crystal growth of polymer molecules. While a low temperature environment could have contrary influences on crystallization behaviors $[7,25,26]$. Intense cooling rate has limited the time needed for a sufficient primary crystallization growth. More crystallizable chain segments were forced to form the secondary crystallization at the end of a rapid cooling.

Values of $n$ implied both EVA and LDPE had homogenous random nucleation followed by threedimensional spherulitic growth in a spherical form. $n$ at various cooling rates arranged between 2.98 4.52 in EVA and 4.80 5.99 in LDPE, respectively. LDPE had a higher dimensionality of crystal growth than EVA. Non-integral $n$ value $>4$ was considered as a result of nucleation rate increasing during interface controlled growth [27]. Crystallization mechanism in the secondary stage is also analyzed. Corresponding apparent $n$ ' of EVA varied from $0.93 \sim 0.96$, and the value of LDPE slightly fluctuates within 0.67 0.77. This referred to a thickening of long cylinders or large lamellae after the spherulites' impingement [27]. The secondary crystallization stage took place in a more restricted surrounding, which needed much longer time than the primary stage. The slow secondary crystallization is positive to the perfecting of the overall crystallization behavior. That is why the annealing treatment during practical manufacturing has positive influence on the final properties of products.

\section{B-Mo's method}

Mo's method [11, 12, 28-30] is another efficient approach derived from the combination of both Avrami equation and Ozawa model [10], which have been successfully utilized in various cases [29, 31, 32]. Dividing the Avrami equation by the Ozawa's equation, functions are given in Equations (7) and (8):

$\log Z_{t}+n \log (t)=\log K(T)-m \log (D)$ 

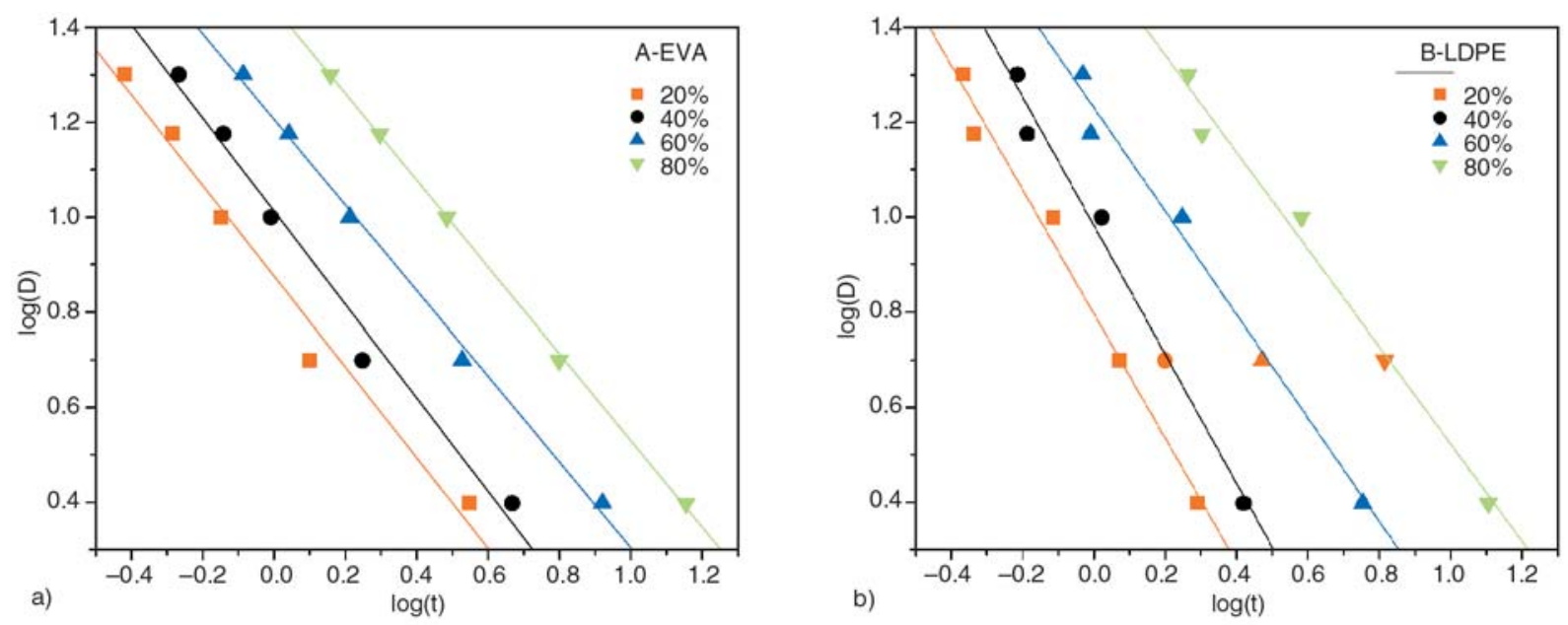

Figure 5. Plots of $\log (D)$ versus $\log (t)$ for neat EVA and LDPE during the non-isothermal crystallization (A-EVA, B-LDPE)

$\log (D)=\frac{1}{m} \log \left[\frac{K(T)}{Z_{t}}\right]-\left(\frac{n}{m}\right) \log (t)$

Parameter $F(T)$ is assumed as $F(T)=\left[K(T) \cdot Z_{t}^{-1}\right]^{1 / m}$. It is denoted as the value of a cooling rate which has to be chosen at a unit crystallization time when the measured sample amounts to a certain degree of crystallinity. $a$ refers to the ratio of Avrami exponent $n$ to the Ozawa exponent $m$. The final form of Mo's method is obtained as Equation (9):

$\log (D)=\log [F(T)]-a \log (t)$

A good linear fitting was obtained by plotting $\log (D)$ against $\log (t)$ as shown in Figure 5. The intercept and slope represent $F(T)$ and $a$, respectively, which were listed in Table 3 . The value of $F(T)$ increased monotonically with the increasing relative crystallinity, implying that under the same time unit, a larger cooling rate was needed in order

Table 3. Data from Mo's method in non-isothermal crystallization kinetic analysis

\begin{tabular}{|c|c|c|c|}
\hline Sample & $\mathbf{X}_{\mathbf{t}}[\mathbf{\%}]$ & $\mathbf{F}(\mathbf{T})$ & $\boldsymbol{a}$ \\
\hline \multirow{4}{*}{ EVA } & 20 & $7.51(0.03)^{*}$ & $0.95(0.08)$ \\
\cline { 2 - 4 } & 40 & $10.29(0.02)$ & $0.98(0.07)$ \\
\cline { 2 - 4 } & 60 & $16.09(0.02)$ & $0.90(0.03)$ \\
\cline { 2 - 4 } & 80 & $27.73(0.01)$ & $0.91(0.01)$ \\
\hline \multirow{4}{*}{ LDPE } & 20 & $6.24(0.02)$ & $1.30(0.09)$ \\
\cline { 2 - 4 } & 40 & $9.54(0.02)$ & $1.28(0.09)$ \\
\cline { 2 - 4 } & 60 & $16.94(0.03)$ & $1.03(0.07)$ \\
\cline { 2 - 4 } & 80 & $35.19(0.05)$ & $0.98(0.07)$ \\
\hline
\end{tabular}

$X_{t}$ :given relative crystallinity; $F(T)$ : non-isothermal crystallization rate parameter from Mo's method; $a$ : slop of plots in Figure 5 (the ratio of Avrami exponent $n$ to the Ozawa exponent $m$ ) *standard error to obtain a higher $X_{t} . F(T)$ accorded well with results from Jeziorny theory. It was suggested that only the primary crystallization stage accounted for the first $20 \%$ crystallization behavior. However, LDPE needed a more intense undercooling condition than EVA to reach the higher $X_{t}=80 \%$. It was the accumulation of both the primary and secondary crystallization stages to obtain a higher $X_{t}$. This suggested that the secondary crystallization in LDPE accounted for comparatively larger contribution to the entirety, or it was slower than in EVA.

\subsubsection{Non-isothermal crystallization of blends}

It is accepted that, like LDPE, crystallizable chain segments in EVA are also continuous ethylene chain segments with different lengths $[18,33]$. As shown in Figure 1, overlapping of exotherms widely existed in blending situation, which was mostly due to the partial miscibility [7] between EVA and LDPE. Both widely used Jeziorny theory and Mo's method suitable for neat polymers, are based on the exothermic enthalpy integration of single exothermic peak. Peak separation, enthalpy integration and fitting would bring inevitable errors in analysis crystallization kinetics. However, variation in the major peak position of each component at EVA/LDPE blends with different ratios indicated their changes in crystallization behaviors under a given crystallization condition. Kinetics information can be investigated via other appropriate approaches, which can avoid the influences from peak overlapping in exotherms. 


\section{A-Apparent activation energy}

The apparent activation energy of each component of blends in non-isothermal crystallization was evaluated via Kisinger's method [34]. Considering influences from cooling rate, the apparent activation energy $\Delta E$ could be determined by Equation (10):

$$
\frac{\mathrm{d}\left[\ln \left(\frac{D}{T_{c}^{p^{2}}}\right)\right]}{\mathrm{d}\left(\frac{1}{T_{c}^{p}}\right)}=\frac{-\Delta E}{R}
$$

where $R$ is the universal gas constant, $\left(8.314 \mathrm{~J} /(\mathrm{mol} \cdot \mathrm{K}), T_{c}^{p}\right.$ is the crystallization peak temperature of each polymer component in blends. $D$ represents the cooling rate. It is suitable to kinetics studying situations even with exothermic peak overlapping. The good linear relation plot of $\ln \left(D / T_{c}^{p 2}\right)$ versus $1 / T_{c}^{p}$ for EVA and LDPE component in blends were shown in Figure 6. As data listed in Table 4, after blending, the $\Delta E$ of both polymer components increased, which indicated the inter-molecular interaction at melt between EVA and LDPE would hinder the nucleation at the beginning of cooling process.

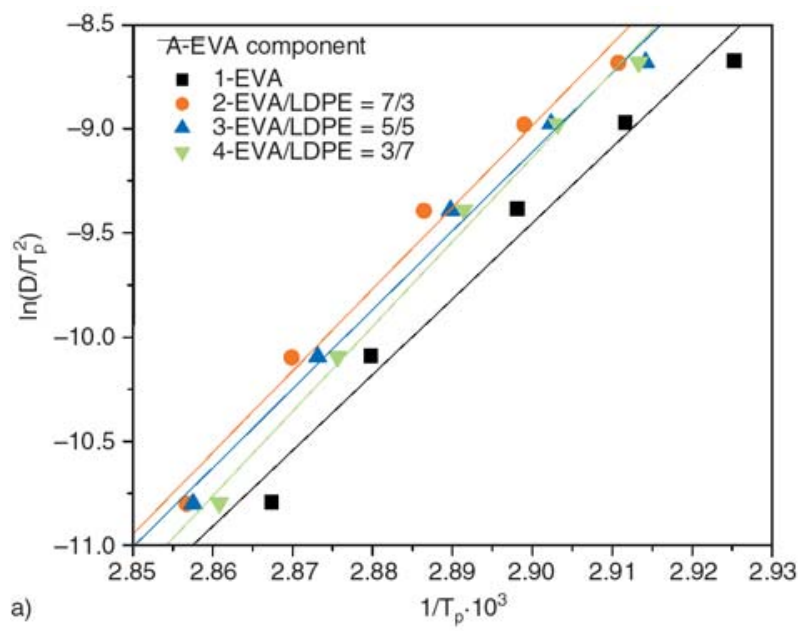

\section{B-Crystallization rate coefficient}

Another similar approach with a crystallization rate coefficient $(C R C)$ parameter, proposed by Khanna [16], and Di Lorenzo and Silvestre [26] was also utilized in this work. As the polymer cooled from melt state $\left(T_{m}\right)$, structures which have symmetrical and short repeating chain segments crystallize sooner than those with longer, unsymmetrical or branched repeating units. Khanna considered the cooling rate $D$ dependence against the exothermic peak temperature $T_{c}^{p}$. It was proposed that, once the crystallization began, it could be hindered by a higher cooling rate. But the amount of hindrance would be the least for the fastest crystallizing polymer. By plotting the dependence of $D\left[{ }^{\circ} \mathrm{C} / \mathrm{min}\right]$ against $T_{c}^{p}\left[{ }^{\circ} \mathrm{C}\right]$, the slope should have a larger value (absolute value) for one crystallized comparatively faster. $C R C$ was finally defined as the $\Delta D / \Delta T_{c}^{p}\left[\mathrm{~h}^{-1}\right]$, representing the variation in cooling rate required for a $1^{\circ} \mathrm{C}$-change in the under cooling of the polymer melt $[26,35]$.

As shown in Figure 7 and Table 5, CRC ranked the materials on a scale of crystallization rate. Blending affected the crystallization of EVA more significantly than LDPE. CRC of LDPE increased after blending since being blended with EVA, and

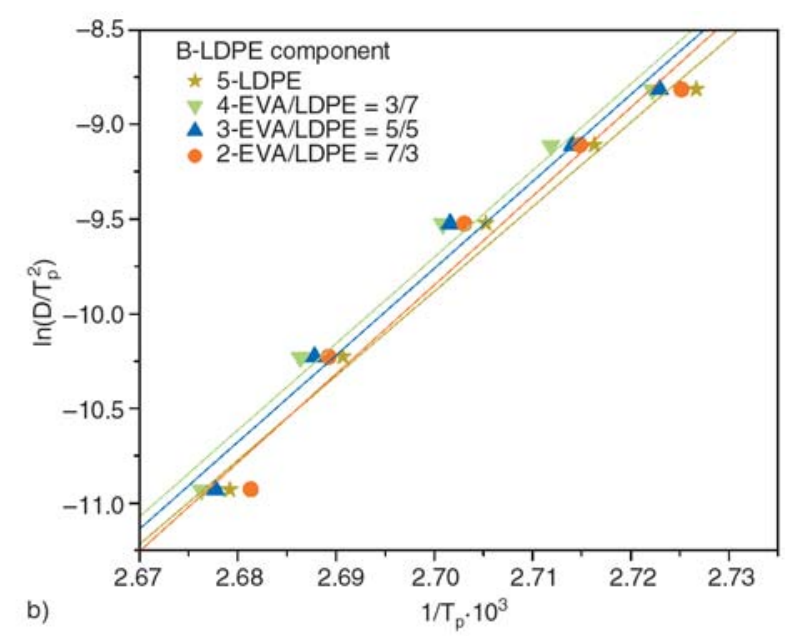

Figure 6. Plots of $\ln \left(D / T_{c}^{p 2}\right)$ versus $1 / T_{c}^{p}$ for EVA and LDPE component in blends (A-EVA component, B-LDPE component)

Table 4. Apparent activation energy of EVA and LDPE components in blends

\begin{tabular}{|l|c|c|c|c|c|}
\hline \multirow{2}{*}{ Component } & \multicolumn{5}{|c|}{$\Delta \mathbf{E}[\mathbf{k J} / \mathbf{m o l}]$} \\
\cline { 2 - 6 } & $\mathbf{E V A}$ & $\mathbf{E V A} / \mathbf{L D P E}=\mathbf{7 / 3}$ & $\mathbf{E V A} / \mathbf{L D P E}=\mathbf{5 / 5}$ & $\mathbf{E V A / L D P E}=\mathbf{3 / 7}$ & LDPE \\
\hline EVA & $302.2(0.9665)^{*}$ & $326.0(0.9769)$ & $315.0(0.9852)$ & $338.1(0.9895)$ & - \\
\hline LDPE & - & $389.6(0.9491)$ & $381.4(0.9693)$ & $379.7(0.9694)$ & $370.7(0.9770)$ \\
\hline
\end{tabular}

*adjust $R^{2}$ of plots fitting 

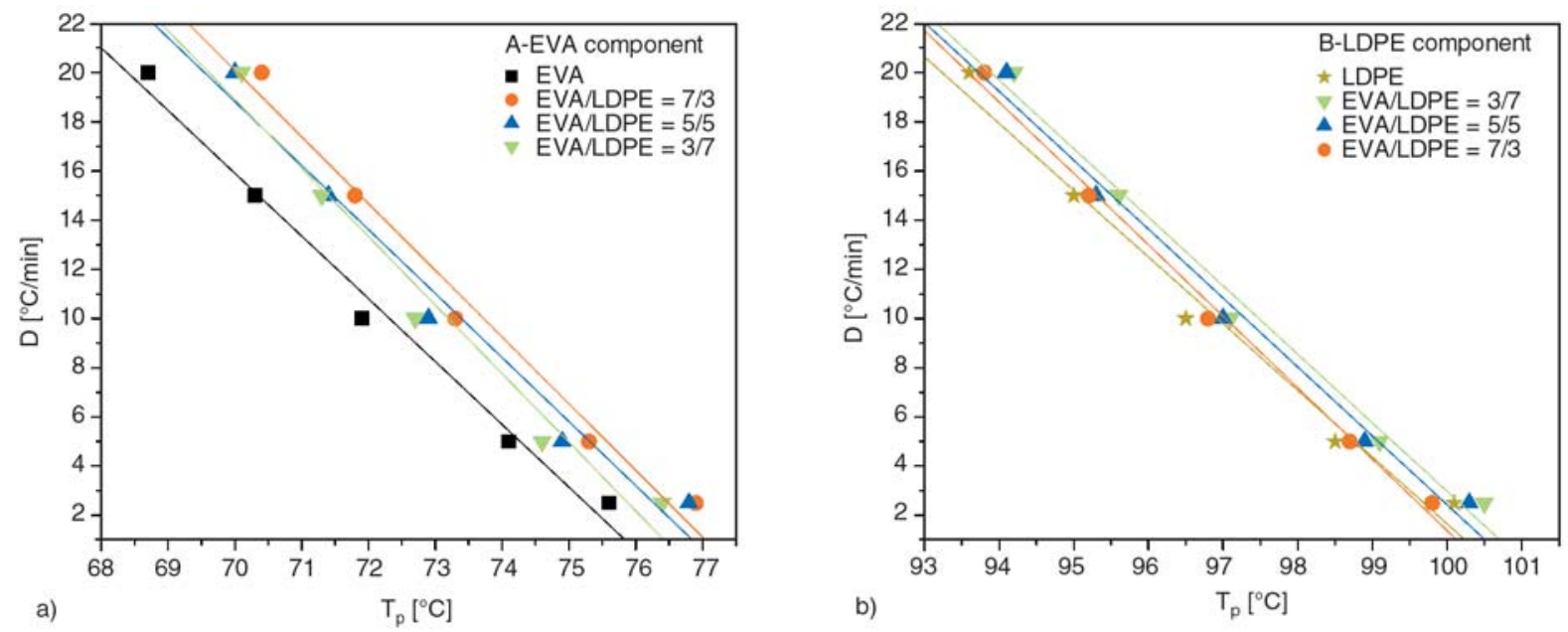

Figure 7. Plots of $D$ versus $T_{c}^{p}$ for EVA and LDPE component before and after blending (A-EVA component, B-LDPE component)

Table 5. Value of $C R C$ for EVA and LDPE components in blends

\begin{tabular}{|l|c|c|c|c|c|}
\hline \multirow{2}{*}{ Component } & \multicolumn{5}{|c|}{ CRC $\left[\mathbf{h}^{-1}\right]$} \\
\cline { 2 - 6 } & EVA & EVA/LDPE $=\mathbf{7 / 3}$ & EVA/LDPE $=\mathbf{5 / 5}$ & EVA/LDPE $=\mathbf{3 / 7}$ & LDPE \\
\hline EVA & $153.0(0.9823)^{*}$ & $162.7(0.9733)$ & $156.0(0.9605)$ & $167.1(0.9538)$ & - \\
\hline LDPE & - & $174.3(0.9919)$ & $168.0(0.9790)$ & $167.2(0.9805)$ & $162.7(0.9733)$ \\
\hline
\end{tabular}

*adjust $R^{2}$ of plots fitting
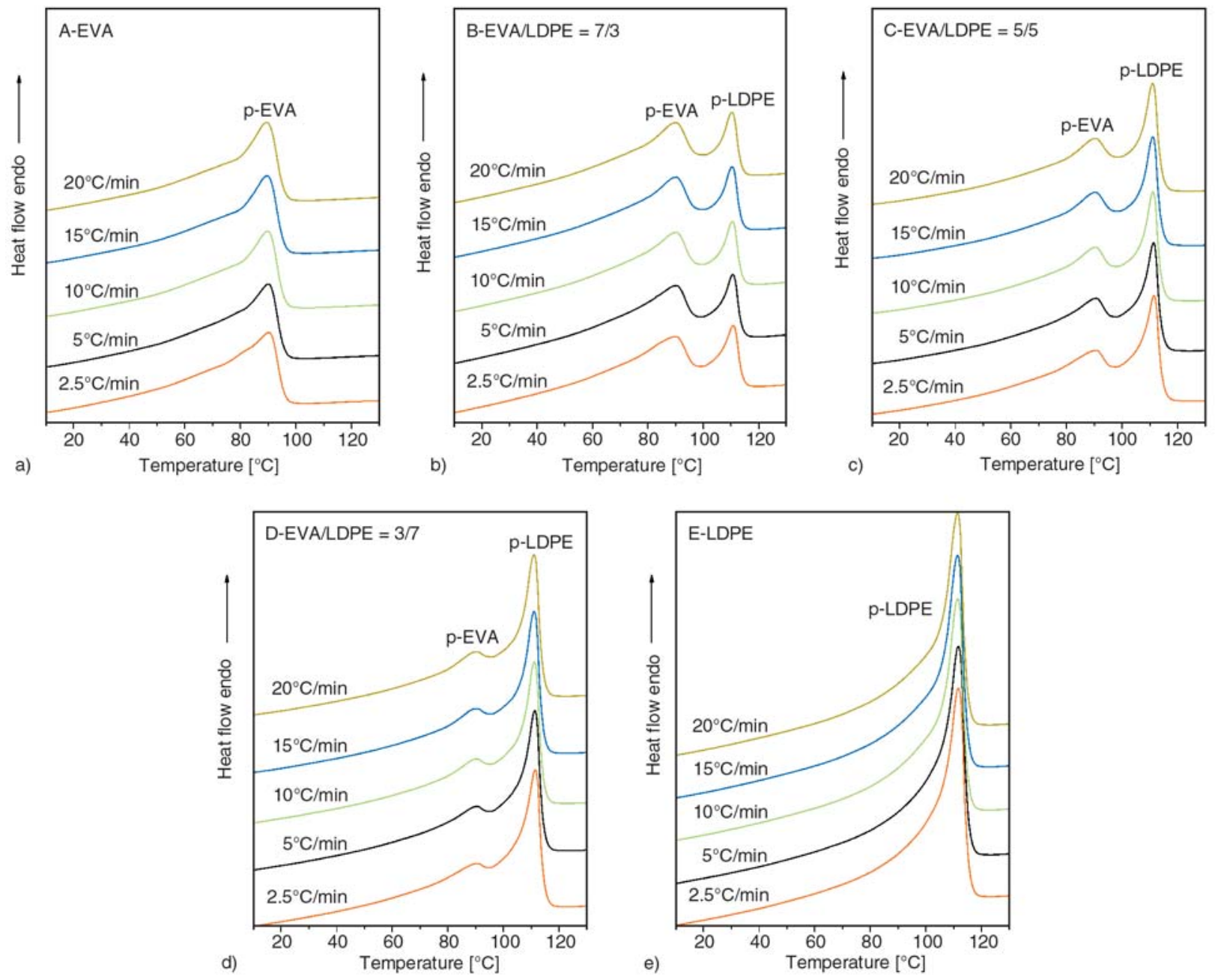

Figure 8. Subsequent melting endotherms of blends corresponding to different cooling rate (A-EVA,

$\mathrm{B}-\mathrm{EVA} / \mathrm{LDPE}=7 / 3, \mathrm{C}-\mathrm{EVA} / \mathrm{LDPE}=5 / 5, \mathrm{D}-\mathrm{EVA} / \mathrm{LDPE}=3 / 7, \mathrm{E}-\mathrm{LDPE})$ 
obtained its maximum $\left(174.3 \mathrm{~h}^{-1}\right)$ in blend of EVA/LDPE $=7 / 3$. Similar $C R C$ growth in EVA component was also observed. The crystallizable units in both EVA and LDPE are symmetrical and short repeating ethylene chain segments. They were firstly randomly mixed in the melt. During the primary crystallization stage of LDPE, EVA is kept in the molten state; its dilution effect prevented the molecules of LDPE from self entanglement, which facilitated the crystal growth of LDPE. The short branches of LDPE were kept at amorphous state until a lower temperature. They formed the secondary crystallization of LDPE, which occurred simultaneously with the crystallization of EVA component as shown in Figures 1B, 1C, 1D. Their partial miscibility led to co-crystallization between two components, which also affected the crystallization rate of EVA component. In blend of $\mathrm{EVA} / \mathrm{LDPE}=7 / 3$, the $C R C$ of LDPE component had the maximum in all cases.

\subsection{Subsequent melting}

The subsequent melting traces of all samples are exhibited in Figure 8 and Table 6. The secondary crystallization in neat EVA and LDPE started to melt at a very low temperature, endothermic behavior grew up gradually and finally formed the major melting peak. This demonstrated that the secondary crystals were the aggregation of defective crystals with various completion degrees. This phenomenon was also confirmed in thermal traces of all blends.

The higher peak (p-LDPE) referred to the primary crystallization melting in LDPE component. While the secondary crystal melting of LDPE incorporated partially with the major melting of EVA component, which resulted in a much broader shape of p-EVA. The slight depression in $T_{m}^{p-L D P E}$ and growth in $T_{m}^{p-E V A}$ also affirmed the partial miscibility between EVA and LDPE. Overlaps in endotherms demonstrated the existence of co-crystallization between them.

Table 6. Subsequent melting data of all samples

\begin{tabular}{|c|c|c|c|c|c|}
\hline Sample & $\begin{array}{c}\text { Sub-heat after } \\
\text { cooled at }\left[{ }^{\circ} \mathrm{C} / \mathrm{min}\right]\end{array}$ & $\mathbf{T}_{\mathbf{m}}^{\mathbf{p}-\mathrm{EVA}}\left[{ }^{\circ} \mathbf{C}\right]$ & $\mathbf{T}_{\mathrm{m}}^{\mathrm{p}-\mathrm{LDPE}}\left[{ }^{\circ} \mathbf{C}\right]$ & $\mathbf{T}_{\mathrm{m}}^{\mathbf{f}}\left[{ }^{\circ} \mathbf{C}\right]$ & $\Delta \mathbf{H}_{\mathrm{m}}[\mathrm{J} / \mathrm{g}]$ \\
\hline \multirow{5}{*}{ EVA } & 2.5 & 90.2 & - & 95.9 & 77.7 \\
\hline & 5.0 & 89.9 & - & 95.7 & 77.1 \\
\hline & 10.0 & 89.7 & - & 95.7 & 76.4 \\
\hline & 15.0 & 89.6 & - & 95.7 & 76.0 \\
\hline & 20.0 & 89.5 & - & 95.7 & 75.8 \\
\hline \multirow{5}{*}{$\mathrm{EVA} / \mathrm{LDPE}=7 / 3$} & 2.5 & 90.1 & 110.8 & 114.1 & 88.7 \\
\hline & 5.0 & 90.3 & 110.7 & 113.9 & 87.3 \\
\hline & 10.0 & 90.3 & 110.4 & 113.8 & 86.1 \\
\hline & 15.0 & 90.2 & 110.4 & 113.7 & 86.4 \\
\hline & 20.0 & 90.2 & 110.3 & 113.7 & 86.1 \\
\hline \multirow{5}{*}{ EVA/LDPE $=5 / 5$} & 2.5 & 90.7 & 111.4 & 114.4 & 104.9 \\
\hline & 5.0 & 90.7 & 111.2 & 114.2 & 104.4 \\
\hline & 10.0 & 90.6 & 111.1 & 114.0 & 102.9 \\
\hline & 15.0 & 90.5 & 110.9 & 114.1 & 102.1 \\
\hline & 20.0 & 90.5 & 110.9 & 114.1 & 101.9 \\
\hline \multirow{5}{*}{ EVA/LDPE $=3 / 7$} & 2.5 & 90.7 & 111.4 & 114.4 & 118.1 \\
\hline & 5.0 & 90.7 & 111.3 & 114.2 & 116.3 \\
\hline & 10.0 & 90.5 & 111.0 & 114.0 & 114.0 \\
\hline & 15.0 & 90.5 & 111.0 & 114.0 & 113.7 \\
\hline & 20.0 & 90.4 & 111.0 & 114.0 & 112.7 \\
\hline \multirow{5}{*}{ LDPE } & 2.5 & - & 111.6 & 115.0 & 133.6 \\
\hline & 5.0 & - & 111.4 & 114.7 & 131.6 \\
\hline & 10.0 & - & 111.4 & 114.7 & 130.8 \\
\hline & 15.0 & - & 111.4 & 114.6 & 129.6 \\
\hline & 20.0 & - & 111.2 & 114.6 & 130.2 \\
\hline
\end{tabular}

$T_{m}^{p-E V A}:$ the major melting peak temperature of EVA component in blends; $T_{m}^{p-L D P E}$ : the major melting peak temperature of LDPE component in blends; $T_{m}^{f}$ : final temperature of melting behavior; $\Delta H_{m}$ : melting endothermic enthalpy 


\section{Conclusions}

The Jeziorny theory and Mo's method were successfully utilized to evaluate the crystallization rate of neat EVA and LDPE. In the primary crystallization stage, LDPE crystallized faster than EVA apparently. Along with the increasing in cooling rate, such rate differences shrank gradually for the lack of primary crystal growth time in polymer. The Avrami index $n$ indicated that both polymers had homogeneous nucleation and crystallized in a three-dimensional spherulitic growth mechanism. LDPE had a higher dimensionality of crystal growth than EVA. $F(T)$ from Mo's method also revealed a tendency that accorded well with results from Jeziorny theory. Blending EVA with LDPE led to apparent overlaps of exotherms during cooling. Inter-molecular interaction between them in the melt increased the activation energy of crystallization at the beginning of cooling. During the primary crystallization stage of LDPE, the dilution effect of liquid EVA prevented the molecules of LDPE from self entanglement, which facilitated the crystal growth of LDPE. The short branches of LDPE kept at amorphous state until a lower temperature. They formed the secondary crystallization of LDPE, which occurred simultaneously with the crystallization behavior of EVA component. Their partial miscibility led to co-crystallization between two components, which also affected the crystallization rate of EVA component. In blend of $\mathrm{EVA} / \mathrm{LDPE}=7 / 3$, the $C R C$ of EVA was higher than that in the neat polymer, LDPE component obtained the maximal $C R C$ value at $174.3 \mathrm{~h}^{-1}$. The subsequent melting further demonstrated the partial miscibility and co-crystallization between EVA and LDPE components in blends.

\section{References}

[1] Takidis G., Bikiaris D. N., Papageorgiou G. Z., Achilias D. S., Sideridou I.: Compatibility of low-density polyethylene/poly(ethylene-co-vinyl acetate) binary blends prepared by melt mixing. Journal of Applied Polymer Science, 90, 841-852 (2003).

DOI: $10.1002 / a p p .12663$
[2] Landete-Ruiz M. D., Martinez-Díez J. A., RodríguezPérez M. A., De Saja J. A., Martin-Martinez J. M.: Improved adhesion of low-density polyethylene/EVA foams using different surface treatments. Journal of Adhesion Science and Technology, 16, 1073-1101 (2002). DOI: $10.1163 / 156856102760146174$

[3] Rodríguez-Pérez M. A., Duijsens A., De-Saja J. A.: Effect of addition of EVA on the technical properties of extruded foam profiles of low-density polyethylene/EVA blends. Journal of Applied Polymer Science, 68, 1237-1244 (1998).

DOI: 10.1002/(SICI) 1097-4628(19980523)68:8 $\leq 1237::$ AID-APP5>3.0.CO;2-E

[4] Borisova B., Kressler J.: Environmental stress-cracking resistance of LDPE/EVA blends. Macromolecular Materials and Engineering, 288, 509-515 (2003). DOI: $10.1002 /$ mame.200390048

[5] Khonakdar H. A., Jafari S. H., Yavari A., Asadinezhad A., Wagenknecht U.: Rheology, morphology and estimation of interfacial tension of LDPE/EVA and HDPE/EVA blends. Polymer Bulletin, 54, 75-84 (2005).

DOI: $\underline{10.1007 / \mathrm{s} 00289-005-0365-6}$

[6] Moly K. A., Radusch H. J., Androsh R., Bhagawan S. S., Thomas S.: Nonisothermal crystallisation, melting behavior and wide angle $\mathrm{X}$-ray scattering investigations on linear low density polyethylene (LLDPE)/ethylene vinyl acetate (EVA) blends: Effects of compatibilisation and dynamic crosslinking. European Polymer Journal, 41, 1410-1419 (2005). DOI: 10.1016/j.eurpolymj.2004.10.016

[7] Shi X. M., Jin J., Chen S. J., Zhang J.: Multiple melting and partial miscibility of ethylene-vinyl acetate copolymer/low density polyethylene blends. Journal of Applied Polymer Science, 113, 2863-2871 (2009). DOI: 10.1002/app.30271

[8] Jeziorny A.: Parameters characterizing the kinetics of the non-isothermal crystallization of poly(ethylene terephthalate) determined by d.s.c.. Polymer, 19, 1142-1144 (1978). DOI: $\underline{10.1016 / 0032-3861(78) 90060-5}$

[9] Ziabicki A., Jarecki L.: Theoretical analysis of oriented and non-isothermal crystallization III. Kinetics of crystal orientation. Colloid and Polymer Science, 256, 332-342 (1978).

DOI: $10.1007 / \mathrm{BF} 01544326$

[10] Ozawa T.: Kinetics of non-isothermal crystallization. Polymer, 12, 150-158 (1971). DOI: $10.1016 / 0032-3861(71) 90041-3$

[11] Ren M., Mo Z., Chen Q., Song J., Wang S., Zhang H., Zhao Q.: Crystallization kinetics and morphology of nylon 1212. Polymer, 45, 3511-3518 (2004). DOI: $\underline{10.1016 / j . p o l y m e r .2004 .03 .027}$ 
[12] Song J., Ren M., Chen Q., Sun X., Zhang H., Song C., Zhang H., Mo Z.: Isothermal and nonisothermal crystallization kinetics of irradiated nylon 1212. Journal of Polymer Science Part B: Polymer Physics, 43, 23262333 (2005).

DOI: $\underline{10.1002 / p o l b .20447}$

[13] Shi X. M., Zhang J., Jin J., Chen S. J.: Non-isothermal crystallization and melting of ethylene-vinylacetate copolymers with different vinyl acetate contents. Express Polymer Letters, 2, 623-629 (2008). DOI: $10.3144 /$ expresspolymlett.2008.75

[14] Goodarzi V., Jafari S-H., Khonakdar H. A., Monemian S. A., Hässler R., Jehnichen D.: Nonisothermal crystallization kinetics and determination of surfacefolding free energy of PP/EVA/OMMT nanocomposites. Journal of Polymer Science Part B: Polymer Physics, 47, 674-684 (2009). DOI: $\underline{10.1002 / \text { polb. } 21672}$

[15] Li S-N., Li Z-M., Yang M-B., Hu Z-Q., Xu X-B., Huang R.: Carbon nanotubes induced nonisothermal crystallization of ethylene-vinyl acetate copolymer. Materials Letters, 58, 3967-3970 (2004). DOI: $\underline{10.1016 / \text { j.matlet.2004.09.005 }}$

[16] Khanna Y. P.: A barometer of crystallization rates of polymeric materials. Polymer Engineering and Science, 30, 1615-1619 (1990).

DOI: $10.1002 /$ pen.760302410

[17] Ying J-R., Liu S-P., Guo F., Zhou X-P., Xie X-L.: Non-isothermal crystallization and crystalline structure of PP/POE blends. Journal of Thermal Analysis and Calorimetry, 91, 723-731 (2008). DOI: $\underline{10.1007 / \mathrm{s} 10973-007-8586-6}$

[18] Li C. X., Kong Q. S., Zhao J., Zhao D. L., Fan Q. R., Xia Y. Z.: Crystallization of partially miscible linear low-density polyethylene / poly(ethylene-co-vinylacetate) blends. Materials Letters, 58, 3613-3617 (2004).

DOI: $10.1016 /$ j.matlet.2004.06.057

[19] Hussein I. A.: Nonisothermal crystallization kinetics of linear metallocene polyethylenes. Journal of Applied Polymer Science, 107, 2802-2809 (2008). DOI: 10.1002/app.27392

[20] Avrami M.: Kinetics of phase change I: General theory. Journal of Chemical Physics, 7, 1103-1112 (1939).

DOI: $10.1063 / 1.1750380$

[21] Avrami M.: Kinetics of phase change II: Transformation-time relations for random distribution of nucle. Journal of Chemical Physics, 8, 212-224 (1940). DOI: $10.1063 / 1.1750631$

[22] Avrami M.: Granulation, phase change and microstructure kinetics of phase change. III. Journal of Chemical Physics, 9, 177-184 (1941). DOI: $10.1063 / 1.1750872$

[23] Cebe P., Hong S. D.: Crystallization behavior of poly (ether-ether-ketone). Polymer, 27, 1183-1192 (1986). DOI: $\underline{10.1016 / 0032-3861(86) 90006-6}$
[24] Run M., Gao J., Li Z.: Nonisothermal crystallization and melting behavior of mPE/LLDPE/LDPE ternary blends. Thermochimica Acta, 429, 171-178 (2005). DOI: 10.1016/j.tca.2005.03.007

[25] Paul D. R., Newman S.: Polymer blends. Wiley, New York (1978)

[26] Di Lorenzo M. L., Silvestre C.: Non-isothermal crystallization of polymers. Progress in Polymer Science, 24, 917-950 (1999). DOI: $10.1016 /$ S0079-6700(99)00019-2

[27] Christian J. W.: The theory of transformation in metals and alloys. Pergamon Press, Oxford (1975).

[28] Liu T., Mo Z., Wang S.: Nonisothermal melt and cold crystallization kinetics of poly(aryl ether ether ketone ketone). Polymer Engineering and Science, 37, 568571 (1997). DOI: $10.1002 /$ pen. 11700

[29] Liu M., Zhao Q., Wang Y., Zhang C., Mo Z., Cao S.: Melting behaviors, isothermal and non-isothermal crystallization kinetics of nylon 1212. Polymer, 44, 2537-2545 (2003). DOI: $10.1016 / \mathrm{s} 0032-3861(03) 00101-0$

[30] Song J. B., Chen Q. Y., Ren M. Q., Sun X. H., Zhang H. L., Zhang H. F., Mo Z.: Effect of partial melting on the crystallization kinetics of nylon-1212. Journal of Polymer Science Part B: Polymer Physics, 43, 3222 3230 (2005).

DOI: $10.1002 /$ polb.20525

[31] Tao Y., Pan Y., Zhang Z., Mai K.: Non-isothermal crystallization, melting behavior and polymorphism of polypropylene in [beta]-nucleated polypropylene/ recycled poly(ethylene terephthalate) blends. European Polymer Journal, 44, 1165-1174 (2008). DOI: $10.1016 /$ j.eurpolymj.2008.01.023

[32] Huang J-W., Wen Y-L., Kang C-C., Tseng W-J., Yeh M-Y.: Nonisothermal crystallization of high density polyethylene and nanoscale calcium carbonate composites. Polymer Engineering and Science, 48, 1268 1278 (2008).

DOI: $10.1002 /$ pen.21087

[33] Jin J., Chen S., Zhang J.: Investigation of UV aging influences on the crystallization of ethylene-vinyl acetate copolymer via successive self-nucleation and annealing treatment. Journal of Polymer Research, in press (2009).

DOI: $10.1007 / \mathrm{s} 10965-009-9374-8$

[34] Kissinger H. E. Variation of peak temperature with heating rate in differential thermal analysis. Journal of Research of the National Bureau of Standard, 57, 217-221 (1956).

[35] Liu T-Y., Lin W-C., Yang M-C., Chen S-Y.. Miscibility, thermal characterization and crystallization of poly(l-lactide) and poly(tetramethylene adipate-coterephthalate) blend membranes. Polymer, 46, 12586 12594 (2005). DOI: 10.1016/j.polymer.2005.10.100 